\title{
Effects of manual therapy and TENSI massage technique on facial aging
}

Danielle Bastos da Silva Ventura ${ }^{1^{*}}$, Patrícia Froes Meyer ${ }^{2}$, Rodrigo Marcel Valentim da Silva ${ }^{3}$, Eneida de Morais Carreiro², Rafaella Rêgo Maia ${ }^{3}$, Laura Vieira Pires Diniz ${ }^{4}$, Stephany Luanna Queiroga Farias ${ }^{4}$.

${ }^{1}$ Centro Universitário de Rio Preto (UNIRP), São Paulo (SP), Brasil; ${ }^{2}$ Centro Universitário do Rio Grande do Norte (UNIRN), Natal (RN), Brasil; ${ }^{3}$ Universidade Federal do Rio Grande do Norte (UFRN), Natal (RN), Brasil; ${ }^{4}$ Universidade Potiguar (UNP), Natal (RN), Brasil.

\section{ABSTRACT}

Background: Skin aging can be delayed through therapeutic resources. In manual therapy, myofascial stretching has been used to mobilize the structures of the skin, fasciae and muscles in order to reorganize the collagen, improving the appearance of the skin. Objective: Investigate the effects of TENSI massage technique, associated or not with firming cream, on skin aging. Methods: The sample consisted of 27 volunteers, over the age of 40 , who had static and/or dynamic wrinkles caused by facial skin aging. The evaluation was performed using the facial evaluation protocol (FEP), photos, morphological analysis of the face by the Dolphin Imaging Software and questionnaires. The volunteers were divided into two subgroups: G1 - Manual therapy with 12 volunteers and G2 - Manual therapy and cosmetics with 15 volunteers. The treatment was carried out in three cycles. Each cycle corresponded to 5 weeks, with two treatment sessions per week for the first 3 weeks and one session per week for the 4th and 5th weeks. The protocol start ed with face cleaning, followed by cutaneous myostretching. Only the G2 used the firming cream together with the therapy. Results: The software analysis showed changes in both groups, with improvement in the paralateronasal line, in the mandibular projection and in the nasolabial angle, however, these were better perceived in the volunteers of the G2. No adverse reactions were reported and few volunteers observed hyperemia at the skin. The firmness of the skin was reported as "Much firmer" in the vast majority of volunteers, as well as the classification in "Excellent treatment". Conclusion: The myofascial stretch caused by the TENSI Method proved to be effective in improving skin aging, however, its results are even more satisfactory when adding firming cosmetics.

Keywords: Manual therapies; Rejuvenation; Therapeutic Massage.

\section{BACKGROUND}

Age-related skin changes can be divided into intrinsic or chronological aging, which is genetically determined; and extrinsic or photoaging, which is marked by cumulative exposure to ultraviolet radiation ${ }^{(1)}$. Clinical and histological changes can be seen through atrophy of the skin, loss of elasticity and turgor, decreased water in the dermis, decreased thickness of the epidermis, flattened keranocytes, decreased size of fibroblasts, among other aspects ${ }^{(2)}$. The first signs of facial aging usually appear in the eye region, followed by forehead wrinkles, eyebrow ptosis and nose angle, atrophy of the labial commissure, loss of the jaw line and neck angle, with accumulation of fat in that region $^{(3)}$. With the objective of delaying facial skin aging, therapeutic resources with a non-invasive characteristic are increasingly being created and, therefore, do not disturb the patient's daily life, as their recovery is usually quick and painless ${ }^{(4)}$.

Among them, it can be highlighted electrotherapy with excitomotor currents, ionization and electrolifting, phototherapy with LASER, LEDs, pulsed light and electromagnetic fields such as electroporation and radiofrequency, facial gymnastics and manual therapy. The use of these resources seeks to improve and promote a rejuvenated skin's appearance ${ }^{(5)}$. Another effective alternative in the treatment of skin aging is the application of cosmetics, and its use is considered an essential practice to obtain better results when associated with other therapies. Thus, to achieve the objective of attenuating the signs present on the skin, the cosmetic formulation must act on different fronts, such as reducing the formation of free radicals, hydrating the corneal layer, lightening age spots, improving dermal and epidermal metabolism ${ }^{(6)}$.

The manual therapy technique has been used as a therapeutic proposal for facial rejuvenation. Due to the aging process being responsible for causing a loss of the natural tone of the skin, this technique aims to attenuate the expression lines, being the manual resistance applied in several ways: alternating, simultaneous or in diagonal patterns ${ }^{(7)}$.

Within the aspects of manual therapy, myofascial stretching has been used. It is a myofascial release technique, which aims to mobilize structures of the skin, fascia and muscles, in order to reorganize collagen, which can soften facial wrinkles, providing the "lifting" effect. Myofascial massage causes the reconditioning of the skin, improving its elasticity and the tensile strength of tissues composed of collagen, with the production of new fibers of better quality, thus minimizing the effects of flaccidity ${ }^{(8)}$ 
In order to improve the scientific evidence on this recent myofascial stretching technique, this study aims to investigate the effects of the manual therapy called TENSI, associated or not with firming cosmetics, with regard to aspects of skin aging.

\section{METHODS}

Research characterization

Experimental study that presents the comparison of the "before and after" treatment. The research was approved by the Ethics Committee of Universidade Potiguar (code: 3.056.157) and was conducted according to the recommendations of the Consolidated Standards of Reporting Trials CONSORT (Consort Transparent Reporting Of Trials, 2010). All volunteers signed an informed consent form prior to the start of the study and the treatment was carried out from August to November 2019.

\section{Population, sample and criteria}

The sample was formed by 35 volunteers, who had static and/or dynamic wrinkles caused by facial skin aging. The inclusion criteria were women, age over 40 years, have above grade II in the Glogau Classification. The inclusion criteria were having performed other cosmetic procedure(s) in the last 12 months, using medication, pastes or creams for rejuvenation, being an alcoholic and/or being a smoker. Participants who do not agree with the procedures or do not adapt to the times and techniques would be discontinued. Therefore, there was a sample loss of 8 volunteers during the protocol, leaving a sample of 27 subjects. These were divided into two groups, G1 - Manual therapy with 12 volunteers and G2 - Manual therapy and cosmetics with 15 volunteers.

\section{Instrument of data collection}

All participants underwent a facial evaluation, which was performed in the pre-treatment and one week after the final session. The Facial Evaluation Protocol (FEP) was used as an instrument for data collection in this research ${ }^{(9)}$, in which the following topics were covered: identification, anamnesis, functional clinical examination, including inspection, with skin color and type, Glogau skin classification, Fitzpatrick phototype classification, Lapierre and Pierard wrinkle classification, skin flaccidity and classification from Tsuji. The registration of the photos was always performed with Iphone XS $\left(\right.$ Apple $\left.^{\circledR}\right)$ camera with resolution of $12 \mathrm{Mp}$. The volunteer was positioned seated, and the records were made in the anterior and lateral view (right and left). The photos underwent an evaluation in the 2D Facial Analysis Software (Dolphin Imaging version 12.0), in which the morphological analysis of the face was performed, before and after the application of the protocol. As a basis for morphological analysis, the following points were used ${ }^{(10,11)}$.

Nasolabial wrinkle - frontal view, formed by the angle of 2 tangent lines between the labial commissure and nasolabial wrinkle, and its increase means that the wrinkle has been repositioned to the medial region (decreased nasolabial folds).

Paralateronasal projection - lateral view, consists of the angle formed by two tangent lines to the lateral nasal and nasolabial projections, indicating an increase in the paralateronasal projection (characterizing the filling in the nasal region), so that the reduction indicates a decrease in flaccidity.

Lateral projection of the mandible - frontal view, the angle formed by two lines tangent to the lateral and lower projection of the zygomatic region, so that its increase means that the projection has decreased (less flaccidity).

Upon completing the established protocol, the volunteers responded to the patient satisfaction analysis questionnaire, Segot-chicq et al. ${ }^{(12)}$ and the Global Aesthetic Improvement Scale (GAIS) Narins $(2010)^{(13)}$, which is used to classify response to treatments, allowing a comparative assessment at different times after the therapeutic intervention.

\section{Procedures}

The procedures were performed in three treatment cycles. Each cycle was carried out in 5 weeks, with two treatment sessions in the first 3 weeks and one session per week in the 4th and 5th weeks. During treatment, all volunteers were placed in the supine position and maneuvers were performed on all faces. It was performed 24 sessions of postponed treatment. In group G1 Manual therapy, the face was cleaned with cleansing lotion, followed by cutaneous myostretching in the regions of the frontal arches, upper and lower zygomatics, mandibular arch, temporal fasciae, parietal temple, parotid, pectoral cervix and pectoral, followed by friction maneuvers and manual vibration. All stretching maneuvers were performed in an ascending and antigravity manner. In group G2 - Manual therapy and cosmetics, the maneuvers used were maintained, however, firming cosmetics were added, a facial fluid "Elixir", composed of hyaluronic acid, Tensi Complex and biosaccharides, which was applied in the therapist's hands before the maneuvers, and at the end a facial mask was applied, composed of Osilift, Hibiscus 
extract, Hyaluronic acid and Sesa flash. The volunteers were instructed to keep their duties as normal, without interrupting any of their daily activities. The reassessments were performed before and after each cycle, with the repetition of the photos at the angles previously described. At the end the volunteers were reassessed by the facial evaluation protocol and the proposed questionnaires were applied.

\section{Data analysis}

The descriptive and inferential statistics of the data were performed using the SPSS 19.0 (Statistical Package for the Social Science- version
19.0). The normality of the data was observed by the Kolmogorov-Smirnov (KS) test. For the intra-group comparison, the t-paired test was applied and in the analysis between the groups, the t-independent test was used. For categorical variables, descriptive analysis was performed on the distribution of absolute frequencies. The level of significance was $5 \%(p<0.05)$.

\section{RESULTS}

The results obtained using the facial evaluation protocol (FEP) are described in table 1, in absolute values (\%).

Table 1. Facial evaluation using the facial evaluation protocol.

\begin{tabular}{|c|c|c|c|}
\hline \multirow[t]{2}{*}{ Evaluation } & & \multicolumn{2}{|c|}{ Result (\%) } \\
\hline & & G1 & G2 \\
\hline & & $42 \%$ & $20 \%$ \\
\hline \multirow[t]{4}{*}{ Skin Color } & Parda & $50 \%$ & $67 \%$ \\
\hline & Black & $0 \%$ & $7 \%$ \\
\hline & Yellow & $7 \%$ & $0 \%$ \\
\hline & Eudermic & $8 \%$ & $0 \%$ \\
\hline \multirow[t]{4}{*}{ Skin type } & Alipc & $25 \%$ & $20 \%$ \\
\hline & Mixed & $50 \%$ & $60 \%$ \\
\hline & Oily & $17 \%$ & $20 \%$ \\
\hline & Type I & $0 \%$ & $0 \%$ \\
\hline \multirow[t]{4}{*}{ Glogau } & Type II & $27 \%$ & $7 \%$ \\
\hline & Type III & $50 \%$ & $93 \%$ \\
\hline & Type IV & $17 \%$ & $0 \%$ \\
\hline & Type I & $8 \%$ & $7 \%$ \\
\hline \multirow{3}{*}{ Phototype } & Type II & $42 \%$ & $40 \%$ \\
\hline & Type III & $42 \%$ & $53 \%$ \\
\hline & Type IV & $8 \%$ & $0 \%$ \\
\hline \multirow[t]{2}{*}{ Wrinkles } & Yes & $100 \%$ & $93 \%$ \\
\hline & Not & $0 \%$ & $7 \%$ \\
\hline \multirow[t]{2}{*}{ Type of wrinkles } & Static & $75 \%$ & $93 \%$ \\
\hline & Dynamics & $25 \%$ & $7 \%$ \\
\hline \multirow[t]{3}{*}{ Tsuji } & Shallow & $100 \%$ & $73 \%$ \\
\hline & Deep & $0 \%$ & $27 \%$ \\
\hline & Grade I & $50 \%$ & $67 \%$ \\
\hline \multirow[t]{3}{*}{ Lapierre and Pierard } & Grade II & $25 \%$ & $13 \%$ \\
\hline & Grade III & $17 \%$ & $20 \%$ \\
\hline & Fine wrinkles & $16,6 \%$ & $25,5 \%$ \\
\hline \multirow[t]{3}{*}{ Modified Fitzpatrick } & Prominent and visible wrinkles & $0 \%$ & $23,7 \%$ \\
\hline & Wrinkles Moderated & $50 \%$ & $50,7 \%$ \\
\hline & Deep Wrinkles & $33,3 \%$ & $0 \%$ \\
\hline \multirow[t]{3}{*}{ Life habits } & Smoking & $0 \%$ & $0 \%$ \\
\hline & Ethics & $25 \%$ & $17 \%$ \\
\hline & Physical activity & $75 \%$ & $83 \%$ \\
\hline \multirow[t]{2}{*}{ Botox } & Yes & $30 \%$ & $27 \%$ \\
\hline & Not & $70 \%$ & $73 \%$ \\
\hline \multirow[t]{2}{*}{ Cosmetics } & Yes & $63 \%$ & $38 \%$ \\
\hline & Not & $38 \%$ & $54 \%$ \\
\hline \multirow[t]{3}{*}{ Sunscreen } & Yes & $70 \%$ & $100 \%$ \\
\hline & Not & $30 \%$ & $0 \%$ \\
\hline & Dry & $25 \%$ & $7 \%$ \\
\hline \multirow[t]{3}{*}{ Main feature of the skin } & Sensitive & $8 \%$ & $13 \%$ \\
\hline & Oily & $25 \%$ & $33 \%$ \\
\hline & Mixed & $42 \%$ & $47 \%$ \\
\hline
\end{tabular}


Regarding the characteristics of the volunteers, there was a predominance of the skin color White and Brown, with the "mixed" type. Hegemony was observed in the presence of wrinkles at rest, with signs of advanced photoaging (Glogau type III) in both groups, however, in Tsuji's classification, the vast majority were classified as "superficial" and only $27 \%$ of G2 were "deep wrinkles", and in the classification of Lapierre and Pierard the majority obtained grade I. It was noted that most of the study's volunteers used sunscreen and practiced physical activity, in addition, few had used Botox, but with the last application more than a year ago. The morphological analysis of the face using the software Dolphin Imaging Brasil - Renovatio, indicated that the changes were more evident in the volunteers of the group that used the techniques combined with cosmetics. The values found were described in table 2.

Table 2. Face morphological analysis

\begin{tabular}{|c|c|c|c|}
\hline & G1 & G2 & P value \\
\hline & Mean $\pm \mathrm{sd}$ & Mean $\pm \mathrm{sd}$ & \\
\hline L-Paralateronasal Projection (1st) & $151,9( \pm 12,9)$ & $147,8( \pm 7,84)$ & 0,42 \\
\hline L-Paralateronasal Projection (2nd) & $140,7( \pm 13,4)$ & $142,1( \pm 9,15)$ & 0,51 \\
\hline $\mathrm{p}$ value & 0,06 & 0,15 & \\
\hline Nasolabial Angle R (1st) & $114,3( \pm 44,8)$ & $106,04( \pm 33,4)$ & 0,09 \\
\hline Nasolabial Angle R (2nd) & $120,3( \pm 50,16)$ & $147,7( \pm 10,05)$ & 0,08 \\
\hline$p$ value & 0,87 & 0,09 & \\
\hline Nasolabial Angle L (1st) & $116,1( \pm 44,09)$ & $115,3( \pm 43,78)$ & 0,95 \\
\hline Nasolabial Angle L (2nd) & $105,6( \pm 73,05)$ & $127,7( \pm 56,3)$ & 0,21 \\
\hline$p$ value & 0,10 & 0,45 & \\
\hline F-Mandibular Lateral Projection R (1st) & $94,04( \pm 20,5)$ & $123,0( \pm 13,02)$ & 0,08 \\
\hline F-Mandibular Lateral Projection R (2nd) & $109,6( \pm 8,78)$ & $128,6( \pm 13,9)$ & $0,04^{*}$ \\
\hline$p$ value & 0,12 & 0,32 & \\
\hline F-Lateral Mandibular Projection L (1st) & $131,5( \pm 11,8)$ & $123,9( \pm 10,7)$ & 0,06 \\
\hline F-Lateral Mandibular Projection L (2nd) & $135,9( \pm 14,6)$ & $141,6( \pm 8,99)$ & $0,04^{*}$ \\
\hline$p$ value & 0,94 & 0,60 & \\
\hline
\end{tabular}

${ }^{\star}$ Note: $p<0.05$, R: right; L: left.

In the parallel-latero-nasal projection, there was a reduction in both groups, indicating an increase in the projection (filling) of the region (fig. 1 a). In the evaluation of the Nasolabial angle (right and left), there was an increase in the values, being more significant in the group that associated the use of the cosmetic. According to the software analysis, the increase in the analyzed angle indicates a reduction in flaccidity (fig. $1 \mathrm{~b}$ ). The values of the lateral projection of the mandible (right and left) obtained a significant increase for the right side $(p=0.04)$ and for the left side $(p=0.04)$, in the comparison between the groups in the second evaluation, and the increase means that there was a decrease in the projection, representing less flaccidity after treatment (fig. 1 c). 


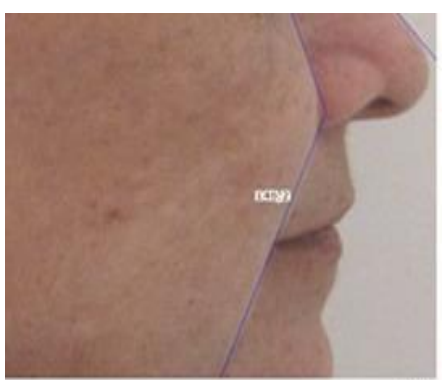

(a)

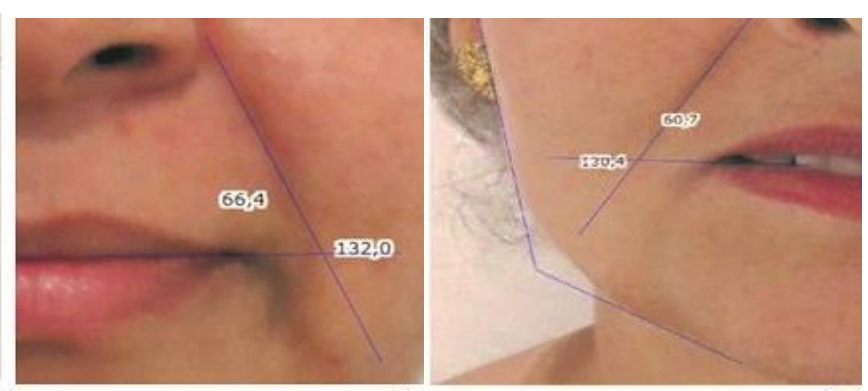

(b)

(c)

Figure 1. (a) Analysis of the nasal lateral parallel projection; (b) Analysis of the Nasolabial angles; (c) Analysis of the lateral mandibular projection.

In the analysis of the applied questionnaires, it was noticed that among the reported reactions, hyperemia in the applied area was not felt in $75 \%$ of the G1 patients, while only $25 \%$ reported the redness. For the $\mathrm{G} 2$ group, $100 \%$ of the volunteers did not report this reaction. For the topic "Improving skin texture", in G1 most volunteers (67\%) reported having their skin "Much firmer compared to 2 months ago", while only $8 \%$ did not feel any difference. In $\mathrm{G} 2$, the answers were divided between "Much firmer compared to 2 months ago" with $47 \%$ and "Firmer compared to 2 months" with $40 \%$, it is noteworthy that in this group, no volunteer observed indifference in the result obtained, however, $13 \%$ felt "Poor firmness" compared to starting treatment. In the analysis of the questionnaire on treatment evaluation, in G1 $67 \%$ of the volunteers reported to be an "excellent treatment", while $33 \%$ reported to be a "good treatment". In $\mathrm{G} 2,75 \%$ reported being an "excellent treatment" and $19 \%$ said it was "Very good treatment". In both groups, all volunteers reported that they would do this aesthetic procedure again.

\section{SKIN TEXTURE}

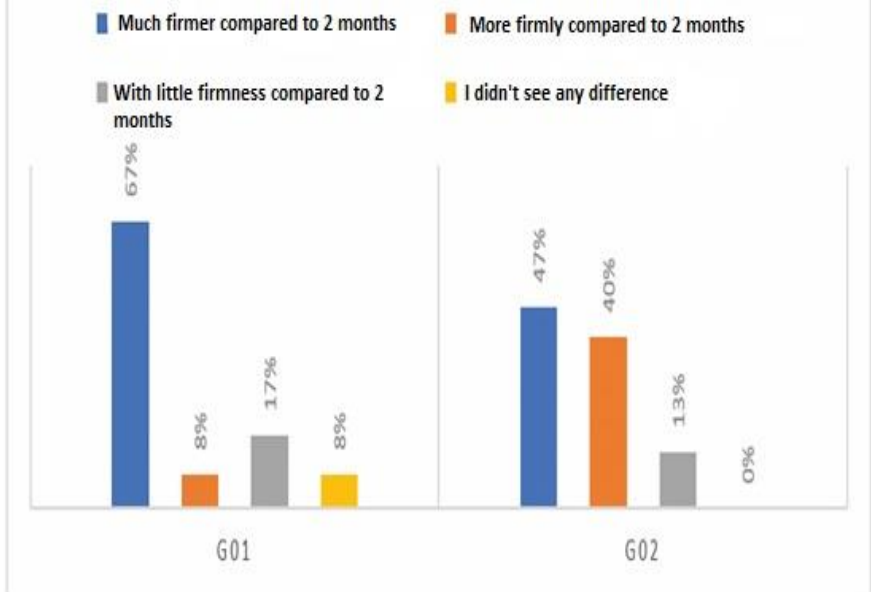

Figure 2. Analysis of the data on the topic "Improving skin texture".

\section{DISCUSSION}

Clinical signs associated with photoaging are characterized by multiple morphofunctional changes in the epidermis and dermis. The application of manual therapy, using myofascial release techniques, stimulates elasticity in the presence of adhered fibers, mobilizing skin structures, fascias and muscles, enabling the reorganization of the present collagen and stimulating a "lifiting" effect in the region ${ }^{(8,14)}$. Therefore, this study sought to clarify the use of manual therapy techniques as a treatment to attenuate the signs of skin aging. The consequent decrease in the thickness of the epidermis, dermis and subcutaneous fat is physically expressed in wrinkles, about $85 \%$ of them in aged skin due to extrinsic factors and are characterized by being $\operatorname{deep}^{(15)}$.

In the present study, there was a greater presence of wrinkles at rest with signs of advanced photoaging (Glogau type III), however, in Tsuji's classification most were classified as "superficial" and in Lapierre and Pierard's classification most of them obtained grade I, expression wrinkles in both groups. The angle measurements analyzed by the software showed changes in both groups, with improvement in the parallel-latero-nasal line, in which there was a greater filling in the area. The increase in the values of the nasolabial angle indicates a reduction in flaccidity, however, only the lateral projection of the mandible (right and left) showed significant values $(p=0.04)$ when comparing the groups.

Corroborating with this study, Silva and collaborators (2013) $)^{(16)}$ analyzed the use of manual therapy as a form of treatment for facial flaccidity in 40 women, divided equally into two groups (control group and experimental group of manual therapy). Significant differences were observed in the left nasogenian sulcus angle, before and after the proposed treatment. Significant clinical improvement was also demonstrated in the comparison of the two groups, according to the 
evaluators, concluding that Manual Therapy can become another resource used in facial rejuvenation. The improvement in the other evaluated angles may be related to the techniques used, which the skin traction generates a "lifting effect" in the region. Manual Therapy maneuvers can act on three factors, being the superficial musculoaponeurotic system, in which traction provides a lifting effect on the face; in the muscles, performing the stretching and adjusting the contraction; and acting on the skin, which indirectly enables vascularization and toning.

As a result, wrinkles are smoothed out, skin ptosis and expression marks are reduced, as well as improved contour definition favoring facial rejuvenation ${ }^{(17)}$. The study of Carreiro et al. $(2012)^{(18)}$ used different techniques for facial rejuvenation, including stretching and strengthening of facial muscles and massage of connective tissue in volunteers attended in an aesthetic treatment program at a university. After 20 treatment sessions, a clinical improvement was observed, with a reduction in Goglau's classification in most volunteers, attenuation of deep wrinkles according to Tsuji and a decrease in the degree of Lapiere and Pierard wrinkles. It was concluded that the program obtained positive results in facial rejuvenation and this was due to the effectiveness of the techniques. It is noteworthy that the results were more evident in the volunteers of the G2 group, this difference found between the groups can be justified by the use of firming cosmetics, which present in their composition active principles considered effective in attenuating the external signs of aging, such as acid hyaluronic. Classified as a non-sulfated glycosaminoglycan, it has a moisturizing, revitalizing and anti-wrinkle action. In the dermis, it promotes the regulation of water balance, osmotic pressure and ion exchange, in addition to functioning as a filter and stabilizing skin structures through electrostatic interactions ${ }^{(19)}$.

Biosaccharides are also used, considered a polysaccharide composition known as rare sugars (L-Fucose, D-galactose, Galacturonic Acid and LRhamnose). They have a great moisturizing power, which promote a softness and smoothness effect on the skin surface, being mainly related to L-fucose (6deoxy-L-galactose), a monosaccharide capable of stimulating fibroblasts, increasing the synthesis of collagen and providing greater firmness to the skin, in addition to acting as an anti-aging asset in helping to decrease the formation of wrinkles and in the attenuation of existing facial wrinkles ${ }^{(20-22)}$. The Hibiscus Extract (Hibiscus sabdariffa), has antioxidant properties, which soften and/or block oxidation reactions induced by free radicals, which can reduce or prevent skin aging. This action is proven by the presence of Alkaloids, Flavonoids and Tannins, which are active plant principles related to antioxidant activities ${ }^{(23,24)}$. Associated with this, the use of the compound Sesaflash ${ }^{\mathrm{TM}}$, which is derived from sesame, acts on skin hydration and oil control, in addition to acting with a tensing action to ensure rejuvenation ${ }^{(25)}$. Regarding satisfaction with the treatment result, the volunteers indicated in a higher percentage that the result was positive, as well as the concepts most cited by them evaluated are "excellent treatment", "very good treatment" and "good treatment", highlighting them the good acceptance of the treatment, in which all volunteers reported that they would perform the procedure again. When asked about the improvement in skin texture, most volunteers felt they were much firmer when compared to the beginning of the study. In addition, no adverse reactions were reported and few volunteers developed hyperemia during the sessions. Thus, manual therapy as a rejuvenating treatment has been considered effective and with good receptivity by patients, as demonstrated in another study ${ }^{(26)}$.

\section{CONCLUSION}

The myofascial stretching caused by the TENSI Method proved to be effective in improving skin aging, favoring improvement in the paralateronasal line, mandibular projection and nasolabial angle after treatment. However, its results are even more satisfactory when added firming cosmetics. The methodology applied during the study, which required frequent treatment sessions and a few months, led to the sample loss of volunteers from both groups, thus making it impossible to distribute the sample equally. Additional studies are suggested using new treatment associations and variation in the evaluation methodology.

Authors' contributions: DBSV and RRM: study design; EMC, LVPD and SLQF: data collection; RMVS: statistical analysis; PFM: critical review of the manuscript. All authors read and approved the final manuscript.

Financial support: Nothing to declare.

Conflict of interest: There are no conflicts of interest.

\section{REFERENCES}

1. Monteiro E. Envelhecimento facial: perda de volume e reposição com ácido hialurônico. RBM. Revista Brasileira de Medicina. 2010;67(8):299-303. 
2. Patriota RC. Estudo do laser Erbium Glass fracionado não ablativo no tratamento do fotoenvelhecimento cutâneo: avaliação clínica, histopatológica, microscopia eletrônica e imunohistoquímica. São Paulo: Biblioteca da Faculdade de Medicina da Universidade de São Paulo, 2013. Tese de Doutorado.

3. Gondim LP, Moreira AC, Vieira KR, Bessa E, Pontes RB. Cinesioterapia facial e microcorrente galvânica no tratamento de rugas. Rev Inspirar Mov Saude. 2010;3(2):18-26.

4. Estrela JV, Duarte CC, Almeida DN, Araruna VR, Da Silva RM, Cavalcanti RL, et al. Efeito do led na flacidez tissular facial. Catussaba Revista Científica da Escola da Saúde. 2014;3(2):29-36.

5. Souza SL, Braganholo LP, Ávila AC, Ferreira AS. Recursos fisioterapêuticos utilizados no tratamento do envelhecimento facial. Revista Fafibe on-line. 2007;1(3):1-2.

6. Bowler PJ. Impact on facial rejuvenation with dermatological preparations. Clinical interventions in aging. 2009;4:81.

7. Guirro ECO, Guirro RRJ. Fisioterapia Dermatofuncional: fundamentos, recursos e patologias. 3. ed. São Paulo, Manole, 2004.

8. Pereira MB, Brongholi K. Avaliação dos efeitos da massoterapia e cinesioterapia no rejuvenescimento facial. Fisioterapia Brasil. 2009;14(68):26-30.

9. Micussi MTAB, Oliveira TC, Meyer PF, Araújo FRG. Protocolo de avaliação facial: uma proposta fisioterápica. Fisioterapia Brasil, Suplemento especial. 2008.

10. Xia, JJ, Gateno J, Teichgraeber JF. New clinical protocol to evaluate craniomaxillofacial deformity and plan surgical correction. Journal of Oral and Maxillofacial Surgery. 2009;67(10):2093-106.

11. Bobek S, Farrell B, Choi C, Farrell B, Weimer K, Tucker M. Virtual surgical planning for orthognathic surgery using digital data transfer and an intraoral fiducial marker: the charlotte method. J Oral Maxillofac Surg. 2015;73(6):1143-58.

12. Segot-Chicq E, Compan-Zaouati D, Wolkenstein P, Consoli S, Rodary C, Delvigne V, et al. Development and validation of a questionnaire to evaluate how a cosmetic product for oily skin is able to improve well-being in women. Journal of the European Academy of Dermatology and Venereology. 2007;21(9):1181-6.

13. Narins RS, Brandt F, Leyden J, Lorenc ZP, Rubin M, Smith S. A randomized, double-blind, multicenter comparison of the efficacy and tolerability of Restylane versus Zyplast for the correction of nasolabial folds. Dermatologic surgery. 2003;29(6):588-95.

14. Bernardo-Filho M, Meyer PF, Bonelli L, Bernardo RB, Santos Filho SD. Fotoenvelhecimento. Rev Fisoter Ser. 2007;2(1):33-9.

15. Menoita E, Santos V, Santos AS. A pele na pessoa idosa. Journal of Aging and Inovation. 2013;2:18-33.

16. Silva RMV, Daams EFCC, Delgado AM, Silva EM, Oliveira HG, Meyer PF. Efeitos da terapia manual no Rejuvenescimento facial. Ter Man. 2013;11(54):534-539.

17. Oncins MC, Freire RMC, Marchesan IQ. Mastigação: análise pela eletromiografia e eletrognatografia. Seu uso na clínica fonoaudiológica. Distúrbios da Comunicação. 2006;18(2):155-65.

18. Carreiro EM, Soares ILO, Silva RM, Oliveira GM, Santos GG, Moraes MD, et al. Tratamento de Rejuvenescimento Facial pela Estética e Fisioterapia Dermato Funcional: Estudo de caso. Catussaba Revista Científica da Escola da Saúde. 2012;1(2):47-54.

19. Sandoval MH, Caixeta CM, Ribeiro NM. Avaliação in vivo e in vitro da eficácia de um produto com associação de vitamina $\mathrm{C}$, ácido hialurônico fragmentado e manose na prevenção do envelhecimento cutâneo. Surgical \& Cosmetic Dermatology. 2015;7(1):37-44.

20. Robert L, Fodil-Bourahla I, Bizbiz L, Robert AM. Effects of L-fucose and fucose-rich oligo-and polysaccharides (FROP-s) on collagen biosynthesis by human skin fibroblasts. Modulation of the effect of retinol, ascorbate and $\alpha$-tocopherol. Biomedicine \& pharmacotherapy. 2004;58(1):65-70.

21. Péterszegi G, Isnard N, Robert AM, Robert L. Studies on skin aging. Preparation and properties of fucose-rich oligo-and polysaccharides. Effect on fibroblast proliferation and survival. Biomedicine \& pharmacotherapy. 2003;57(5-6):187-94.

22. Robert C, Robert AM, Robert L. Effect of a preparation containing a fucose-rich polysaccharide on periorbital wrinkles of human voluntaries. Skin Research and Technology. 2005;11(1):47-52.

23. Silva JN, Teixeira RTBB, Ramos SHS, Santos VL, Coelho CP, Saliba WA, et al. Desenvolvimento de um creme dermatológico vegetal rejuvenescedor facial contendo extrato de hibiscus sabdariffa. Brazilian Journal of Surgery and Clinical Research. 2019;25(2):1118. 
24. Da-Costa-Rocha I, Bonnlaender B, Sievers H Pischel I, Heinrich M. Hibiscus sabdariffa L.-A phytochemical and pharmacological review. Food chemistry. 2014;165:424-43.
25. Vorster A. The magical ingredients: anti-ageing. South African Pharmaceutical and Cosmetic Review. 2013;40(8):22-5.

26. Dessy LA. Noninvasive physical treatments in facial rejuvenation. International Textbook of Aesthetic Surgery. 2016;978-3-662-46598-1. 